\title{
Positive Management Tools in Education Management
}

\author{
Irina Nikolaevna Efremkina ${ }^{1 *}$, Elena Vladimirovna Liksina ${ }^{1}$, Valerii Liusev ${ }^{1}$, and Natalia \\ Vladimirovna Osipova ${ }^{1}$ \\ ${ }^{1}$ Federal State Budgetary Educational Institution of Higher Education "Penza State Technological \\ University", Faculty of Automated Information Technologies, Faculty of Automated Information \\ Technologies, Department of Pedagogy and Psychology, Penza, Russia
}

\begin{abstract}
The purpose of the study is to identify the problem areas in education management and the opportunities to apply positive management tools. The authors believe that it is possible to diminish the issues related to authoritarian education management by using the tools and principles of positive psychology, specifically, positive management connected to addressing the human factor. The authors note the inefficiency of strict and regulated methods of education management as it often requires unorthodox, original solutions. The article contains the results of the pilot study of education workers' subjective perception of a positive management tool engagement. The survey method has been utilized for the study. The analysis of the data has resulted in the following conclusions: 1) it has been found that the positive management tools identified through the analysis are insufficiently used in education management; 2) the identified problem areas in education management are related to expectations for work, satisfaction with the evaluation and feedback, interpersonal relations, as well as career and development.
\end{abstract}

\section{Introduction}

Teachers and students are the main resource of an educational institution and largely determine its success or decline. We consider this the main resource because such qualities as qualification, performance and (ir)responsible attitude to one's duties highly depend on teachers and students themselves unlike material and financial resources.

In a sense, pedagogical activity can be seen as creative as it often requires unorthodox, original decisions which determines the inefficiency of strict, regulated management methods.

How should the management system be designed to ensure the maximum efficiency of every worker and help their competences reach the full potential?

Unfortunately, the analysis of management practices in many organizations and companies, both public and private, indicates that most managers maintain authoritative, strict management principles believing them to be the most efficient. Education institutions

\footnotetext{
* Corresponding author: eamdom@yandex.ru
} 
are not an exception. On the one hand, these principles strengthen control over employees' activities. On the other hand, total control can cause resistance or suppression of initiative.

We believe that it is possible to diminish the issues related to authoritarian education management by using the tools and principles of positive psychology, specifically, positive management.

Addressing the human factor as "an important reserve of social development, increase of productivity, education efficiency, management and other types of socially influencing individuals" [1, p. 3] can become a possible approach.

Positive management is impossible without considering motivation.

The issue of motives for actions and motivation as a whole is currently urgent for modern psychology and has practical, methodological and theoretical significance. Psychological studies on such matters as motivation for activity and goal-setting play a key part. According to B.F. Lomov (1999), "Studying these issues is essential not only for the development of the theory of psychology but also for solving other practical tasks" [2, p. 155].

In the work "The New Positive Psychology", M. Seligman noted that when a person puts into practice their particular advantages, the work brings them the greatest satisfaction, and "corporations that encourage this approach leave the firms that offer employees merely financial satisfaction far behind" [3, p. 218].

At the same time, according to N.V. Samoukina, one needs to consider employees' psychological types to develop motivational conditions. One can roughly identify three such types.

"1) employees who favor internal rewarding factors - striving to achieve the result, interesting work content, the social importance of work, communication with colleagues (type A employees);

2) employees who are the most responsive to external rewarding factors - salary, career, symbols of their position (personal car, office, power, etc.), recognition, additional privileges (credits, insurances, etc.) (type B employees);

3 ) employees who value a combination of factors - both internal and external rewards (type C employees)" [4, p. 20].

Therefore, N.V. Samoukina concludes, "for the personal approach to non-financial stimulation of key employees, one must determine each employee's psychological type and apply the factors they consider important" [4, p. 20].

Practitioners believe that the highest level of motivation in an organization is staff engagement that means that employees are interested in the company's success, are ready to invest time and effort into developing and implementing plans, making decisions, etc. It is noted that employees' results of organizational engagement are manifested in low turnover, increased productivity, and motivation is the means of increasing engagement [5, p. 87]. Engagement must be continuously evaluated. Thus, for example, the Gallup Institute developed the Q12 tool for this purpose - a survey comprised of four blocks: career and development, the mission of the organization, recognition and values and interpersonal relationships $[6,7]$.

When Elton Mayo analyzed the results of the now commonly known Hawthorne experiments, the scholar emphasized the employees' internal position, degree of satisfaction with the work performed, psychological climate and management styles [8]. Modern researchers also mention the importance of caring about employees and note that as "organizational life is not static, the requirements for work are increasing due to rapid technological changes" which, in turn, should prompt the employer to "train the employees, consider their abilities and potential" [9, p. 291, 293]. Researchers consider job satisfaction to be "a crucial factor in increasing work productivity and forming an individual's positive opinion of their work which is related not only to the level of salary but also the social value of work and working conditions. Otherwise, burnout and stress occur" [10, p. 860]. 
Modern managers-practitioners, namely, K.V. Lashkevich, note that reducing the impact of stress factors through improving the moral and psychological climate in the organization is becoming essential for managing a modern organization. Foreign researchers, in particular, S. Sonnentag also link stress factors at work not only to individual wellbeing but also psychological detachment from work [11, p. 169]. According to K.V. Lashkevich, interactive anonymous surveys in the corporate newsletters helps to monitor the changes in the climate. For example, we have used the platform Happy Job for this purpose" [12]. Moreover, researchers note the significance of team-building training sessions and the combination of corporate and private goals.

In turn, this requires managers to avoid the directive management style and use the coaching style when the manager wants to teach the employees independent decision-making and the participative style which entails participation in management, trust, delegating and common responsibility.

F. Laloux, the author of the "colorful organizations" theory, states that the current management is obsolete [13]. The business coach names self-management as an essential feature of an organization of the future.

There are seven "colorful" stages of organizational development, according to F. Laloux, however, at the first two stages, the organization is being founded, and the other five stages are related to the evolution of the organization: Red, Amber, Orange, Green and Teal paradigms.

The "Red" and "Amber" organizations are characterized by standardized, bureaucratic management, a strict or even rigid chain of administrative command. "Orange" organizations are characterized by competition, merit-based power and responsibility.

At the level of the "Green" organization, significant opportunities arise for the employees' self-fulfillment, as they become more interested which is based on organizational goals.

F. Laloux names self-managing and self-organizing the key features of a "Teal" organization.

We believe that neither the "Green" and especially nor the "Teal" levels of organization development are possible without the formation of an appropriate organizational culture which is largely consistent with the results of modern research. In particular, L.S. Vereshchagina and L.A. Olkhova, in the study on the example of a university, conclude that work motivation is connected to the type of organizational culture [14], and Polish researchers link positive management with work motivation oriented towards scientific efficiency [15].

Therefore, the purpose of the study is to identify problem points in education management through the employees' subjective perception as well as the opportunities to apply positive management tools.

The study was based on the assumption that there are problem areas in education management that have a negative impact on employee motivation and job satisfaction, interpersonal relationships and emotional state of employees.

To achieve the goal of the study, it was necessary to solve the following problems: 1) select adequate diagnostic tools, 2) create a sample, 3) conduct diagnostics and interpret the results obtained in the study.

\section{Methods}

The survey was the main method of the study. In the spring of 2020, in Penza, as part of a pilot study, we conducted a survey of teachers from educational institutions of three levels general secondary, secondary vocational and higher education. We used a 12-factor engagement survey (Gallup Q12) [6,7] as well as a questionnaire specially developed for this study, all questions of which were formulated according to the purpose of the study. It is 
worth noting that continuous sampling does not apply to the object of this study since it includes a large number of teachers, clearly over 1,000 people. Therefore, the method of sampling was applied which was based on the principle of randomness. The sample reflected all the essential categories of the object of study. A total of 72 people were surveyed during the pilot study. The sampling error of the study is $\pm 11 \%$.

The sample included employees of educational organizations in Penza including $27 \%$ of respondents from general secondary education, $24 \%$ from secondary vocational education and $49 \%$ from higher education. The average length of employment in educational organizations among respondents was 9.9 years. It is worth noting that the study involved pedagogical workers, as well as employees of management and administrative branches of educational organizations.

The aforementioned 12-factor survey usually includes four operating blocks: expectations from work (what I will get); satisfaction with assessment and feedback (recognition and value); team (interpersonal relationships); development (career and development).

\section{Results and Discussion}

Let us address the results of the diagnostics obtained through the engagement survey.

Quantitative and qualitative analysis of the data obtained in the study made it possible to identify certain problem areas.

For example, almost a quarter of the respondents (24.1\%) noted the absence or scarcity of materials and tools necessary for high-quality work. We believe that this was especially evident in the conditions of the forced transition to distance learning when many teachers faced strict requirements for the quality of the education process, on the one hand, and the lack of technical capabilities, on the other.

$37.9 \%$ of respondents indicated that the employer did not sufficiently consider the employees' potential and abilities since their organizations did not have the conditions to fulfil their potential and it was not always possible to do what they could do best. In many respects, in our opinion, this is due to the lack of a system of identification and development of the employees' potential and competencies in many educational organizations.

$41.4 \%$ of the surveyed said that they had not received recognition or praise for good work during the past week. Meanwhile, recognition is not merely a positive assessment for a job well done. First, it is a positive emotional interaction that can become a factor in a person's attachment to the organization. At the same time, both Russian and foreign authors note that "attracting, encouraging employees and helping them grow increases their motivation, and neglect of these issues leads to problems" [16, p. 188].

There are a lot of responders who do not feel that management cares about employees as individuals $(44.8 \%)$.

The same number of respondents $(44.8 \%)$ indicated the lack of friends (friend) at work. However, it should be noted, as many studies show [17, 18], a sufficiently large number of employees expressed a need to form and maintain long-term stable relationships which implies a significant degree of closeness and trust. The absence of a friend (friends) at work can lead to a decrease in emotional attachment to the team and, as a result, to the organization as a whole.

About a quarter of respondents indicated that over the past six months no one at work had spoken to them about their successes and noted the lack of opportunity to learn and grow at work. Far from everyone feels that managers are interested in their professional growth and development.

Researchers note that "the efficiency of the work of a company is largely determined by employee job satisfaction, a favorable social climate, which, on the one hand, reduces turnover and, on the other hand, increases the level of motivation and expands psychological 
abilities" [16, p. 2]. In particular, B. Gulski provides a review of studies that confirm the connection between positive management and positive emotions, employees' interpersonal relationships, as well as its role in organizational development [19, p. 201].

The analysis of the respondents' answers to the questionnaire indicated the following.

Only $16 \%$ of respondents stated that studies of work motivation and socio-psychological climate were carried out regularly. The overwhelming majority of respondents (up to 74\%) noted that such actions are either did not occur or were extremely rare. Conducting sociopsychological training sessions aimed at unity and team building was also not systematic but extremely rare, according to $68 \%$ of respondents.

According to the surveyed, in almost half of the educational organizations $(47 \%)$, managers prefer the authoritarian management style. In about a third of educational organizations, the democratic style is utilized. Only $16 \%$ of respondents described the management style as coaching or participative.

Moreover, according to the respondents, most educational organizations where they work can be classified as "Red"/"Amber" and "Orange" - with standardized, bureaucratic management, a strict or even rigid chain of administrative command, competition, meritbased power but devoid of warm human relations. This choice was made by $73 \%$ of respondents.

The results are confirmed by the data of both Russian and foreign researchers. Thus, M. Kiziloğlu notes that "the increasing managerial pressure, a negative motivation that causes an increase in the intention to leave work and stress at work" remains a pressing issue [20, p. 2-3].

Researchers explain low job satisfaction by "maladaptive interpersonal relationships, high workload, low salary, lack of professional development, absence or insufficiency of materials and equipment, chain of command and instability at work" [21, p. 242-243].

\section{Conclusion}

We believe that the data obtained from the analysis allow us to make a conclusion about the presence of problem areas in education management associated with expectations from work, satisfaction with evaluation and feedback, interpersonal relationships as well as career and development which prevents the pedagogues' competences from reaching their full potential.

Therefore, one can recommend the following as positive management instruments in an educational organization.

1. Study and consider the employees' psychological types when developing motivational conditions.

2. Consider and foster employee engagement to identify the areas of the management's increased attention and response.

3. Examine and develop a favorable moral and psychological climate in an educational organization.

4. Study the management style and strive to use the coaching and participative style.

Both Russian and foreign researchers are focused on studying employee engagement, satisfaction and motivation primarily in corporate structures and companies. The education sphere is at the periphery of such studies. Therefore, we believe that research into the connection of management styles, work motivation, loyalty and "internal resignation" of education employees is an interesting direction for future research from a practical application standpoint.

\section{References}


1. V.G. Aseyev, Motivation of behavior and personality formation (Mysl, Moscow, 1976)

2. B.F. Lomov, Methodological and theoretical problems of psychology (Nauka, Moscow, 1999)

3. M. Seligman, The New Positive Psychology: A Scientific Look at Happiness and the Meaning of Life (Publishing house "Sofia", Moscow, 2006)

4. N.V. Samoukina, Effective motivation of staff at minimal cost (Feniks, Rostov-on-Don, 2014)

5. P.S. Smirnov, Organizatsionnaya psikhologiya 9(1) 81-95 (2019)

6. L. Leonova, Gallup Q12 Employee Engagement Survey (Hurma, 2019). Available at: https://hurma.work/ru/blog/vovlechennost-personala-oprosnik-gallup-q12/

7. R.S. Russell, Getting In-depth with the Gallup Q12 Employee Surveys. C.A. Short Company. Available at: https://www.cashort.com/blog/getting-in-depth-with-thegallup-q12-employee-surveys

8. M. Elton, The Human Problems of an Industrial Civilization (Harvard University, Boston, 1945)

9. T.-Ye. Kim, S.C. Schuh, Y. Cai, J. Manag. Stud. 57(2), 287-313 (2020)

10. J. Khalatbari, Sh. Ghorbanshiroudi, M. Firouzbakhsh, Proc. Soc. Behavioral Sci. 84 860-863 (2013)

11. S. Sonnentag, Res. Organ. Beh. 38 169-185 (2018)

12. Konstantin Lashkevich on ways to reduce stress levels in a company (Finparty, 2019). Available at: https://finparty.ru/opinions/157351/

13. F. Laloux, Discovering the organization of the future (Mann, Ivanov and Ferber, Moscow, 2016)

14. L.S. Vereshchagina, L.A. Olkhova, Organizatsionnaya psikhologiya 9(3) 57-73 (2019)

15. B. Beata, L. Krzysztof, M. Szuflita-Żurawska, Entrepreneurial Bus. Econ. Rev. $7237-$ 250 (2019)

16. A. Ahmed, M. Jabeen, F. Mansha, Kh. F. Ali, F. Shaukat, J. Organ. Behav. Res. 4(2) 118 (2019)

17. L.Th.M. Loan, Ph.M. Sean, H.Th.M. Chinh, B.M. Duc, Organizatsionnaya psikhologiya 9(2) 32-51 (2019)

18. W.A. Kahn, J. 33(4) 692-724 (1990)

19. B. Gulski, Hard management and positive management as an idea for management, Scientific Papers of Silesian University of Technology, Organization and Management Series 199-214 (2018)

20. M. Kiziloğlu, J. Organ. Beh. Res. 3(2) 1-12 (2018)

21. S. Kurt, B. C. Demirbag, J. Organ. Beh. Res. 3(2) 242-253 (2018) 